\title{
Seismic damage mechanism of slope and lining in the mountain tunnel portal section
}

\author{
Hua $\mathrm{Xu}^{{ }^{*}}$, Runfang Sun ${ }^{1}$, Jingsong $\mathrm{Xu}^{2}$, Yinfei Tang ${ }^{3}$, Peng Zhang ${ }^{1}$ \\ ${ }^{1}$ School of Civil Engineering, Southwest Jiaotong University, Chengdu, Sichuan 610031, China \\ ${ }^{2}$ Yunnan Communications Investment \& Construction Group Co., Ltd., Kunming, Yunnan, 650032, China \\ ${ }^{3}$ China Railway Siyuan Group Southwest Survey and Design Co., Ltd., Kunming, Yunnan, 650200, China
}

\begin{abstract}
A series of numerical simulations were conducted to study the seismic response in the mountain tunnel portal section. The seismic damage mechanism, including slope cracking and landslide, rockfalls and collapse, and lining cracking were analyzed based on the seismic damage characteristics of the Longxi tunnel during the 2008 Wenchuan earthquake in China. The results show that slope cracking due to the huge horizontal seismic inertial force which exceeds the strength of slope; landslide is caused by the connected cracks where the oblique component of horizontal seismic inertia force exceeds the shear strength of slope; rockfalls and collapse are caused by the cumulative tensile stress in loose soil and rock which exceed the strength of slope; the transverse lining cracks due to the alternate tensile and compressive action of the seismic load along the axial direction, which makes the lining tensile strain accumulates and exceeds the concrete ultimate strength. As for the longitudinal lining cracking, the transverse seismic load makes the bending moment direction in lining alternates, leading to the strength reduction of concrete. Moreover, the circumferential penetrating rupture zone is caused by the large shear force resulting from the slope sliding, which leads to the stress concentration at vault and when the tensile stress exceeds the concrete tensile strength, the vault begins to crack, and then the cracks extend from the arch shoulder to foot.
\end{abstract}

\section{Introduction}

Portal sections of mountain tunnels are the throat for entering and exiting. Due to the poor geological conditions, the peak acceleration of the surface is large, and it is strongly affected by earthquakes. It often suffers from severe seismic damage, such as the collapse of a slope, the burial of a tunnel, and rockfalls. Retaining structures and tunnel portals, cracked linings, staggered platforms, and even collapses, etc. [1-3]; it is prone to cause traffic interruption, huge difficulties in emergency rescue and seismic damage repair in tunnels. In recent years, China has experienced frequent earthquakes, and existing and newly built mountain tunnel portals in high-intensity mountain face huge seismic risks.

At present, scholars have carried out some studies on the seismic damage of the tunnel portal sections. Tao et al. [4] obtained the acceleration amplification effect of the surrounding rock of portals through the shaking table tests and analyzed the most unfavorable position and deformation characteristics of the internal force of the cross-section lining. Zhao et al. [5] found that the strain energy in the plastic zone can comprehensively reflect the stress and strain development of the lining structure through the strength reduction method combined with shaking table tests. Sui et al. [6] obtained that support in the form of frame beams can be used to reduce the internal force of the structural section of the tunnel portals through shaking table tests. Liu et al. [7] derived theoretical and numerical simulations that iterative changes in maximum principal stress will aggravate lining damage, and the farther away from the portals, the smaller the peak displacement. Wu et al. [8] obtained numerical simulations that the lining cracking was the most severe within the range of $93 \mathrm{~m}$ of the tunnel under the effect of the axial Rayleigh wave, and the cracking mode of the lining was simulated. Shen et al. [9] analyzed the failure mode of the lining by seismic damage investigation and numerical simulations. In general, the researches on the seismic damage of mountain tunnel portals are mainly focused on the factors affecting seismic damage [10], the characteristics of seismic damage [11-14], and the law of seismic response [15-18]. Seismic damage mechanisms regarding slopes and lining are still less analyzed, however.

The portal of the Longxi tunnel, which was severely damaged during the 5.12 Wenchuan earthquake in China, was selected as the case. Numerical methods were used to analyze the seismic response of the slope and lining at the tunnel portal section, and to investigate the types and characteristics of seismic damage on the site. The seismic damage mechanism of the mountain tunnel portal was studied systematically. The results can not only deepen the understanding of the seismic damage

\footnotetext{
*Corresponding author's e-mail: xuhua@home.swjtu.edu.cn
} 
mechanism of the mountain tunnel portal, but also guide the seismic design and construction.

\section{Project profile}

The portal of the Wenchuan end of the Longxi tunnel is only $4 \mathrm{~km}$ away from the macro epicenter of the 5.12 Wenchuan earthquake in China (Figure 1). The tunnel is $3658 \mathrm{~m}$ long and belongs to an extra-long tunnel. The soil layer of the slope is a quaternary deluvium with a thickness of several meters to more than ten meters. The vegetation on the surface is dense and there are no adverse geological phenomena such as landslides and collapse. The angle of the slope is about $35^{\circ}$. The tunnel axis obliquely intersects with the slope. Seismic damage on the slope at the tunnel portal of mainly includes slope cracking, collapse, rockfalls, etc.; lining damage mainly includes horizontal and vertical cracks, surface peeling, staggered platforms, and circumferential rupture zones (Figure 2).

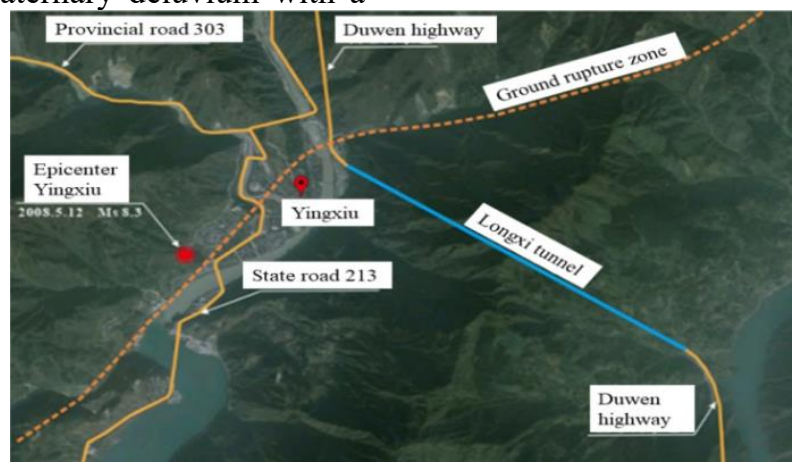

Figure 1. Location of the Longxi tunnel
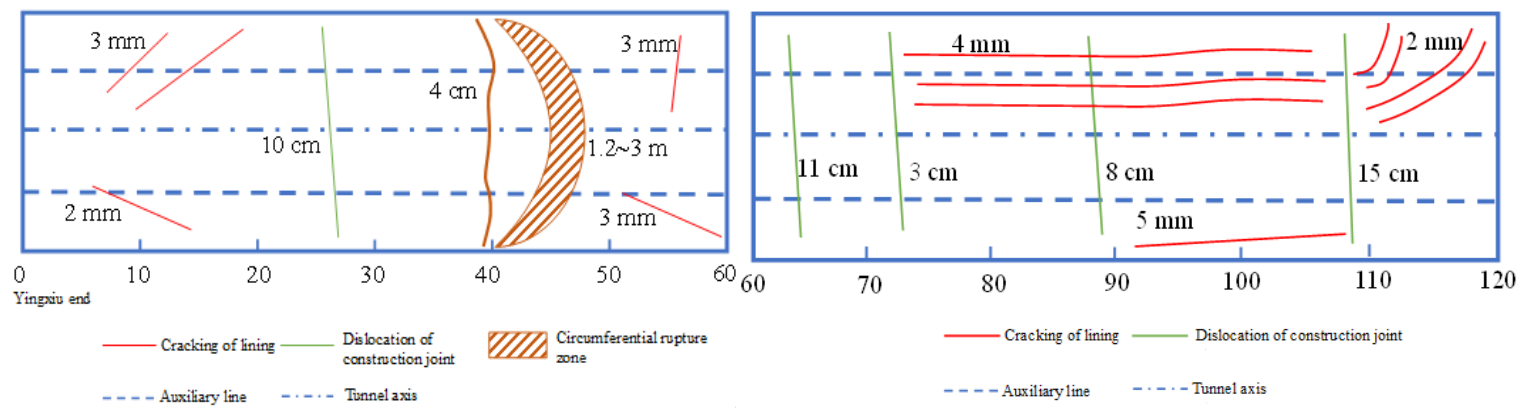

Figure 2. Surface development of lining damage at the Longxi tunnel

\section{Numerical model and parameter}

\subsection{Numerical model}

With full consideration of the terrain and geological conditions, the finite-difference software FLAC3D was used to establish a $120 \mathrm{~m}$ severely damaged portal of the Longxi tunnel. A three-dimensional numerical model was established for seismic calculation and analysis. The model has an axial length of $120 \mathrm{~m}$, a width of $80 \mathrm{~m}$, and a maximum burial depth of $65 \mathrm{~m}$. The overburden is silty clay and gravel soil, and the depth of the rock mass below is $35 \mathrm{~m}$. The lithology is mudstone (Figs 3 and 4). The typical cross-section parameters of the lining are adopted. The support is C20 shotcrete with a thickness of $20 \mathrm{~cm}$; the lining is $\mathrm{C} 25$ concrete with a thickness of 40 $\mathrm{cm}$.

\subsection{Parameters}

The surrounding rock and support are simulated by solid elements, using the Mohr-Coulomb model, and the lining is simulated by shell elements (Table 1).

Table 1. Physical and mechanical parameters of the surrounding rock and lining

\begin{tabular}{cccccc}
\hline Materials & $\begin{array}{c}\text { Elastic Modulus } \\
(\mathrm{GPa})\end{array}$ & $\begin{array}{c}\text { Poisson's } \\
\text { ratio }\end{array}$ & Density $\left(\mathrm{kN} / \mathrm{m}^{3}\right)$ & $\begin{array}{c}\text { Cohesion } \\
(\mathrm{MPa})\end{array}$ & $\begin{array}{c}\text { Internal friction } \\
\text { angle }\left(^{\circ}\right)\end{array}$ \\
\hline Bedrock & 30 & 0.20 & 25.0 & 1.1 & 55 \\
Surrounding rock & 1.8 & 0.32 & 19.0 & 0.4 & 35 \\
Overlay & 0.5 & 0.35 & 14.0 & 0.35 & 32 \\
Support & 21 & 0.2 & 20 & $/$ & $/$ \\
Lining & 29.5 & 0.2 & 24.5 & $/$ & $/$ \\
\hline
\end{tabular}




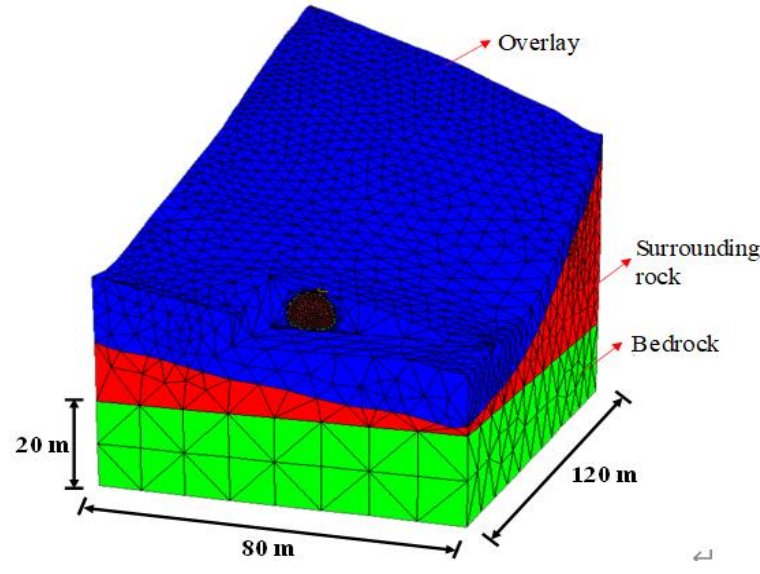

Figure 3. Numerical model of the portal section

\subsection{Ground motion parameters}

The Wolong seismic record with a duration of $50 \mathrm{~s}$ was recorded during the 2008 Wenchuan earthquake in China, and the acceleration time-history after filtering and baseline correction is shown in Figure 5. The Longxi tunnel is only about $4 \mathrm{~km}$ from Yingxiu Town, the

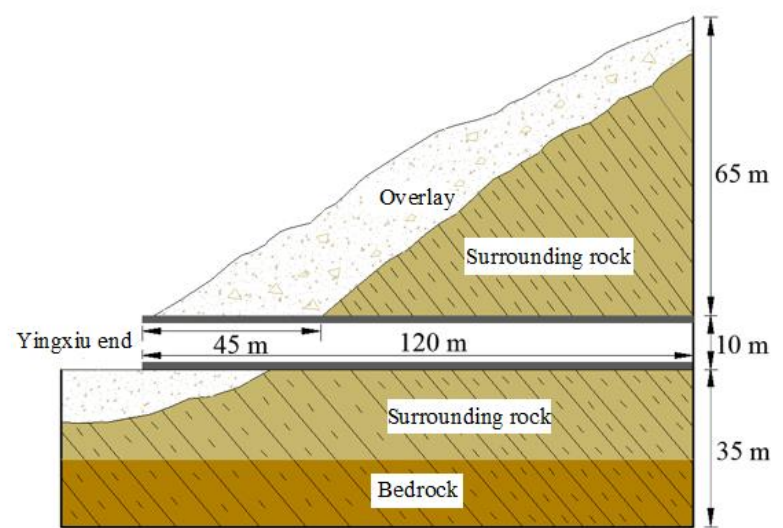

Figure 4. Longitudinal section of the portal section

epicenter of the Wenchuan earthquake. Therefore, the acceleration time-history of the three directions of the seismic wave is loaded from the model bottom, and the loading intensity is $0.95 \mathrm{~g}$. Free-field boundaries are applied around the model. The local damping was performed.

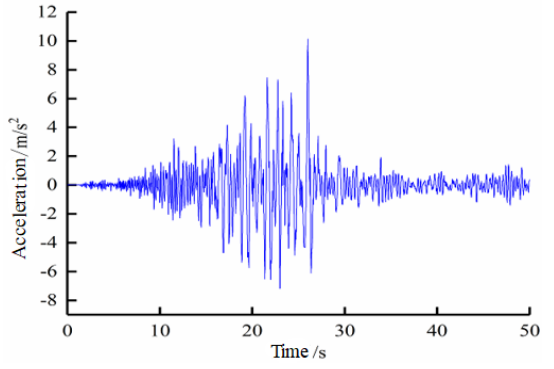

(a) Axial acceleration

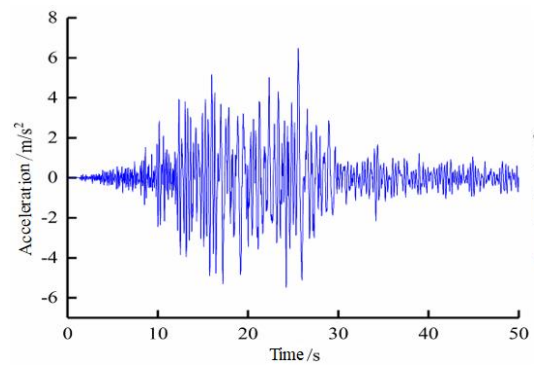

(b) Transverse acceleration

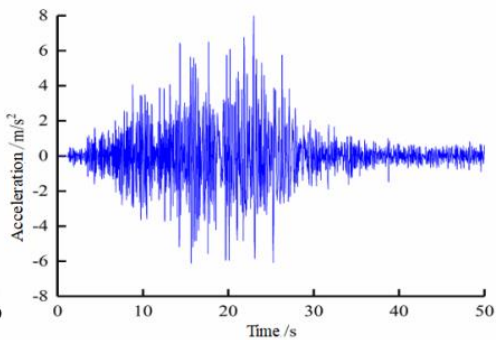

(c) Vertical acceleration

Figure 5. Acceleration time-history of Wolong wave at three directions

\section{Seismic damage mechanism of tunnel portal section}

According to the field investigation and seismic damage characteristics $[11,12,14,15]$, the typical seismic damage of the Longxi tunnel portal mainly includes slope cracking and landslide, rockfall and collapse, lining cracking, circumferential rupture zone, etc. Based on the seismic response and characteristics, the seismic mechanism was analyzed to provide reference for the seismic design.

\subsection{Slope cracking and landslide}

According to previous studies, tensile cracks and shearing slip plane is an important feature of seismic damage of slopes [19]. In order to study the mechanism of cracking and landslide in tunnel portals, the distribution of plastic zone and shear strain rate were analyzed.

Figs 6 and 7 show that a large area of shear failure occurred on the slope of the tunnel portal, and the shear and tensile failure area on the near-mountain side was significantly more than that on the other side; the failure mainly occurs in the deluvium and eluvium. Slope cracking is caused by tensile plastic zone on slope surface. According to the field investigation, the slope surface nearing the tunnel portal is generally loose overburden with low strength. Under the seismic horizontal inertial force, the slope surface is subject to tension (Figure 6), which is prone to "tear" the surface to form cracks, especially in original-crack-existing places. 


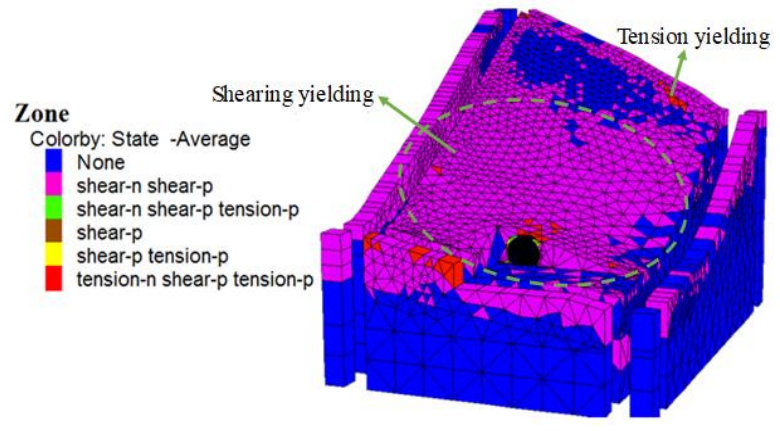

Figure 6. Zone state of tunnel portal slope

It can be seen from the contour of shear strain rate (Figure.7) that the tunnel slope has formed a potential sliding surface under the seismic loading. The landslide is a result of various factors. First, after the forming of surface cracks, the oblique component of the horizontal seismic inertia force makes the slope cracks extend further. Second, with the continuous vibration, the cracks in the slope gradually expand, providing channels for underground water, thus causing a lower shear strength of the loose overburden. Third, with weak surfaces in the slope, the slope may slide along these surfaces [20]. The root is that the oblique component of the seismic inertia force and the slope weight force is greater than its shear strength, resulting in the gradual crack expansion.

\subsection{Rockfall and collapse of the tunnel slope}

It can be seen from Figure 6 that a tensile plastic zone has been formed locally on the top back of the slope, indicating that the rock masses are subjected to a huge tensile force under seismic inertial forces. Due to the lower mechanical performance and developed joints and fissures of the rock mass the tensile strength is extreme low or even zero. When the seismic wave transmits from the bedrock to the strongly weathered rock masses, its energy can be significantly amplified, causing a larger seismic inertial force. Under the huge tension, the tensile stress in the loose soil and strongly weathered rock mass

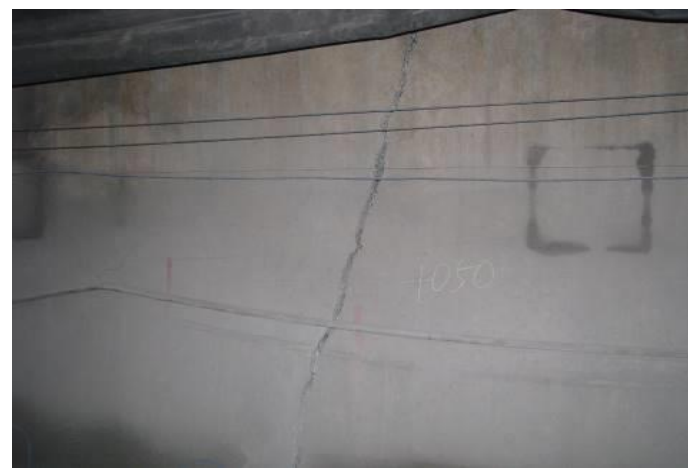

(a) Transverse and oblique cracking of the lining

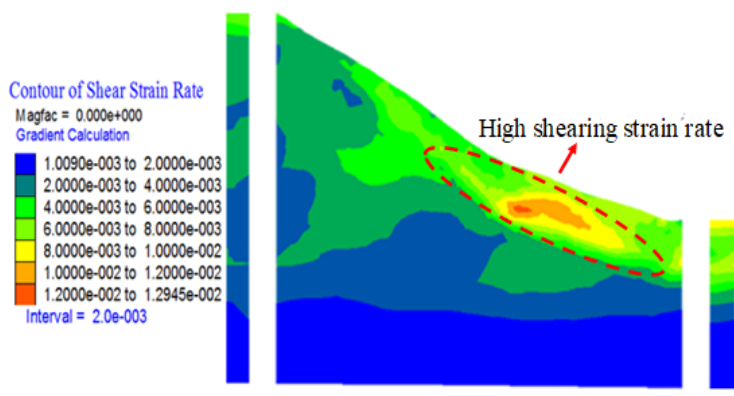

Figure 7. Contour of shear strain rate portal slope

surface can gradually accumulate. When it exceeds the tensile strength of the rock mass and soil itself, they can be thrown to the slope foot, resulting in the rockfall and collapse (Figure 8).

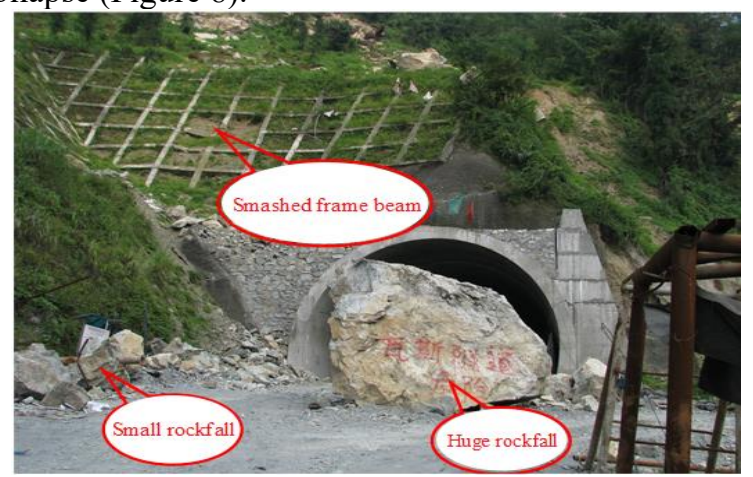

Figure 8. Rockfall and broken frame beam

\subsection{Cracking of tunnel lining}

The investigation shows that the lining cracks are transverse, oblique (Figure. 9 (a)) and longitudinal (Figure. 9 (b)). The transverse and oblique cracks are mainly distributed on the sidewall, and the longitudinal cracks are mainly distributed on the vault, arch shoulder, sidewall and arch foot.

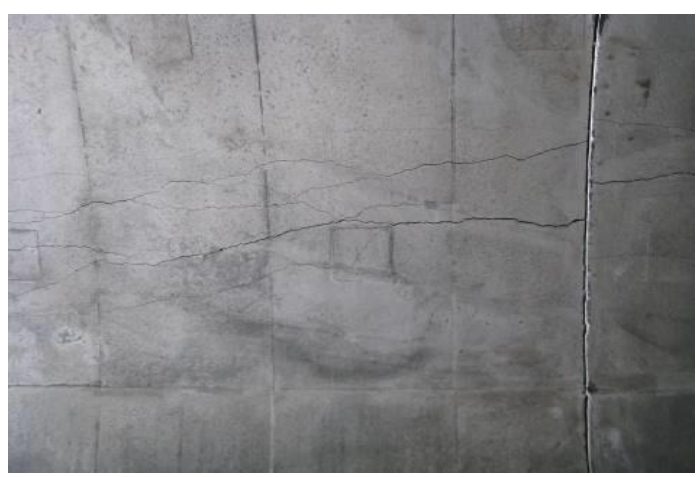

(b) Longitudinal cracking of the lining

Figure 9. Details of the lining damage at the left tunnel

\subsubsection{Variation of lateral and longitudinal bending} moments of the lining. Figure 10 shows the time-history curve of the bending moments of the lining.
It can be seen from Figure 10 that the vertical and horizontal bending moments vary dramatically, indicating a back-and-forth deformation under horizontal transverse and longitudinal seismic loads. 


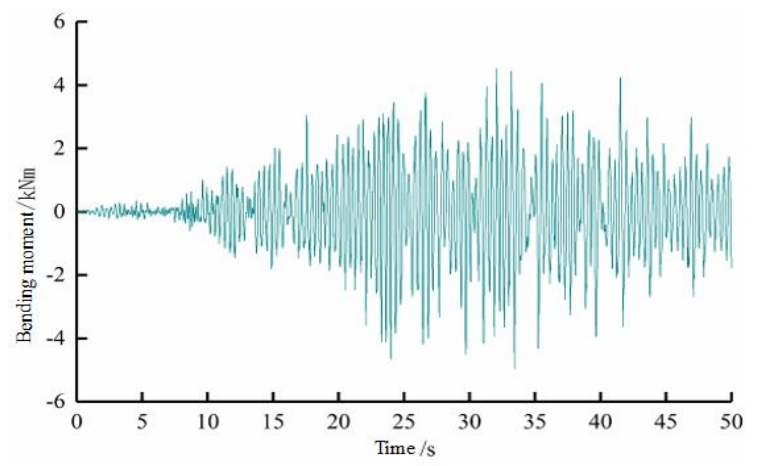

(a) Lining transverse bending moment

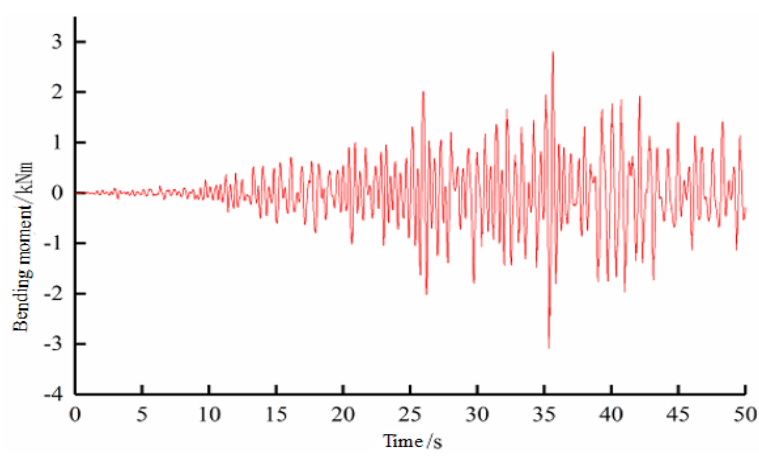

(b) Lining longitudinal bending moment

Figure 10. Transverse and longitudinal bending moment time history of lining

4.3.2. Seismic damage mechanism. According to Figure 10 and the field investigation, the mechanism of lining cracking is that the direction variation of bending moments leads to the alternate changing of the direction of tensile and compressive stress in lining.
As for the horizontal and diagonal cracks (Figure 11), due to the small epicentral distance, seismic waves transmit through the tunnel at a small angle. S-wave generate an alternate tension and compression along the tunnel axis, or jointly acts with $\mathrm{P}$-wave, thus generating a bending deformation [21] and an accumulated dynamic strain in lining [22]. when the strain of concrete exceeds its limit [23], the transverse cracks occur.

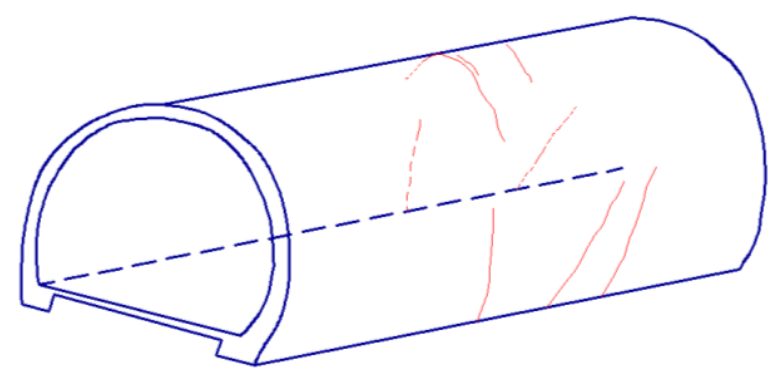

Figure 11. Schematic graph of transverse and oblique cracks in the lining

For the longitudinal cracking of lining, the initial stress state of the lining under static loading (weight and surrounding rock pressure, etc.) is shown in Figure 12 (a). Under the transverse seismic loading, additional bending moments with rapidly alternate directions are generated, resulting in the transverse back-and-forth deformation of lining and surrounding rock. The stress mode of lining is shown in Figure 12 (b-d). These transverse deformation modes lead to an additive effect (Figure 12 (e-f)). The vault, arch shoulder, sidewall, arch foot, and invert are subjected to alternate tension and compression in a very short period of time. On the one hand, the bearing capacity of the concrete reduces significantly; on the other hand, the tensile strain of lining accumulates rapidly. When the cumulative strain of the concrete exceeds the its ultimate strain, it can crack longitudinally [9]. Therefore, the longitudinal cracks of lining are mostly observed on the vault, arch shoulder, sidewall, arch foot, and invert under alternate tension and compression (Figure 13).

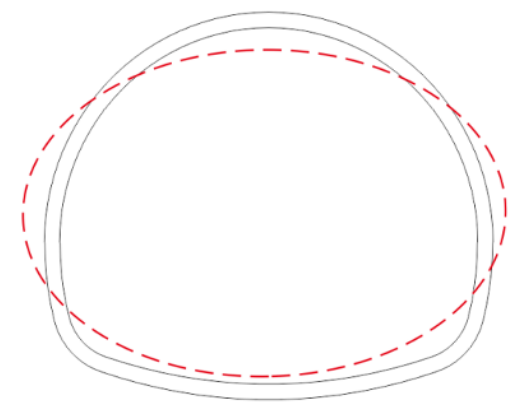

(a) Initial state of lining under static load (b)
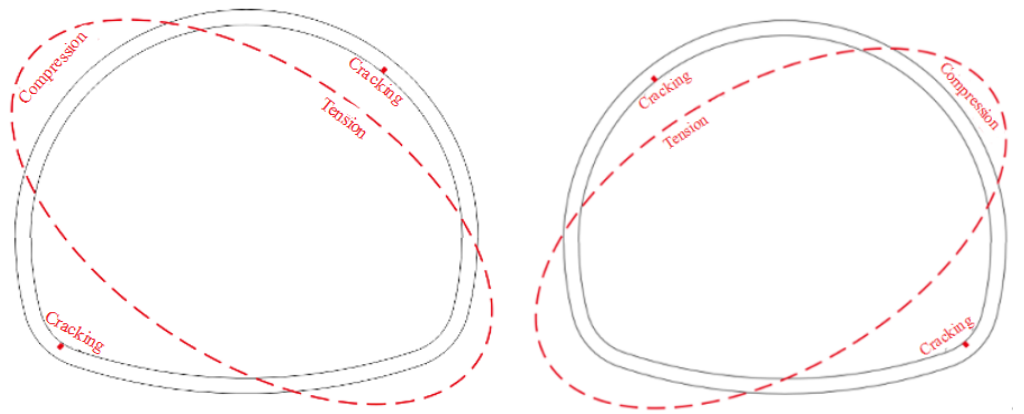

(b) State of lining under transverse bending moment (c) State of lining under transverse bending moment 

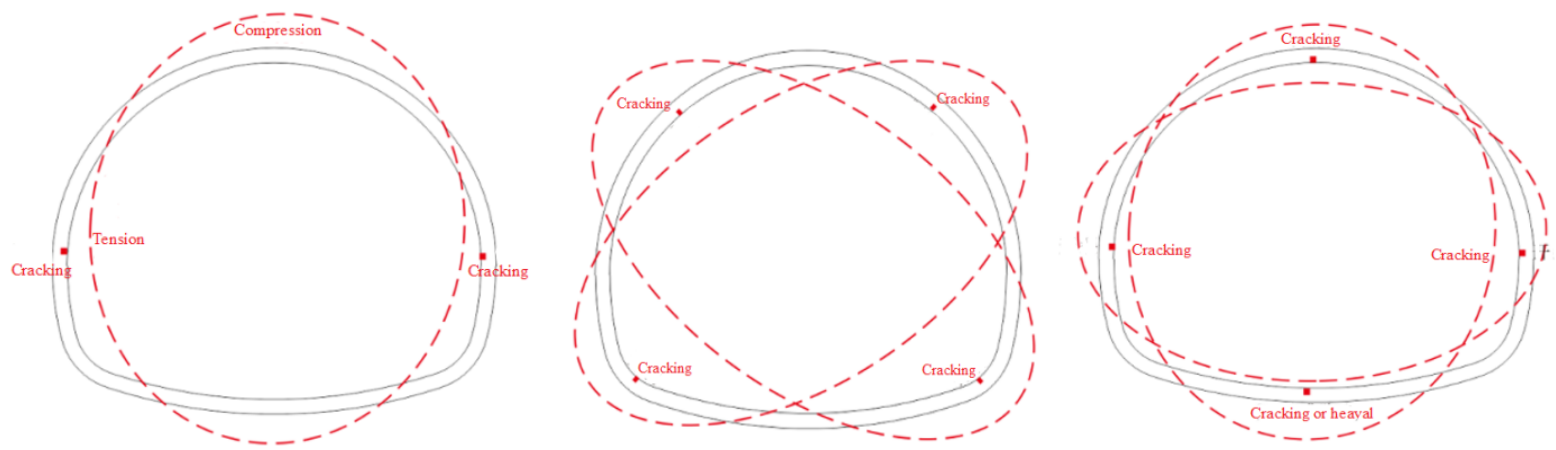

(d) State of lining under transverse bending moment (e) State of lining under alternating transverse bending moment (f) State of lining under alternating transverse bending moment

Figure 12. Schematic graph of longitudinal cracking of lining

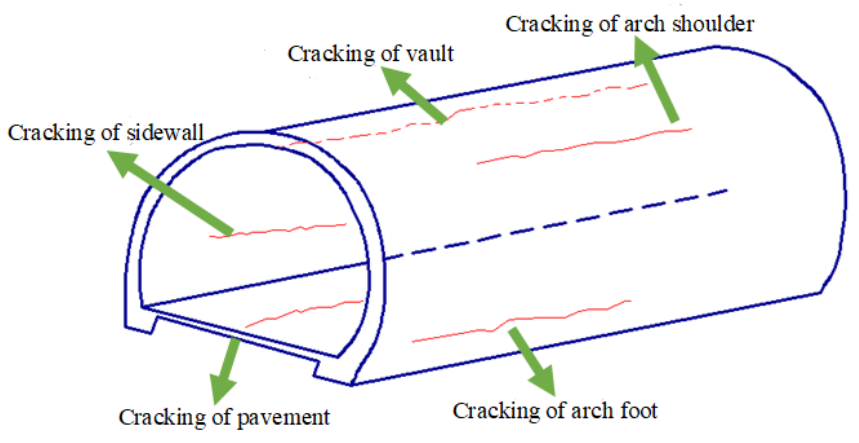

Figure 13. Schematic graph of longitudinal cracks in lining

\subsection{Circumferential rupture zone}

A width of $1.2-3.0 \mathrm{~m}$ circumferential rupture zone caused by the earthquake was observed at $40-45 \mathrm{~m}$ from the tunnel portal (Figure 14). As shown in Figure 14, the concrete peeled off and was crushed, the steels bended inward and the width of pavement cracks are $2-4 \mathrm{~cm}$. The attitude of the bedrock-overburden interface is almost identical with the tunnel axis. In order to study the mechanism of the circumferential rupture zone, the principle stresses and shear force are analyzed in this section.

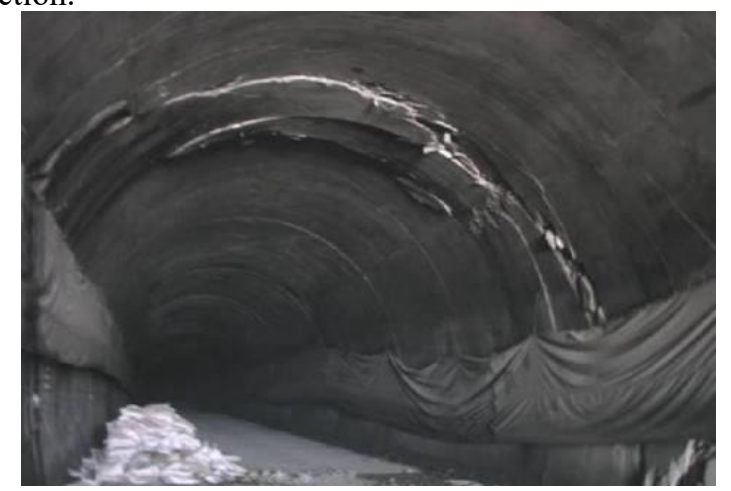

Figure 14. Circumferential crack in the bedrock-overburden interface
4.4.1. Principle stresses nearing the bedrock-overburden interface. Under the strong earthquake, the maximum principle tensile stress of the lining is about $1.0-6.0 \mathrm{MPa}$. The minimum principle compressive stress is about $-1.0-11.0 \mathrm{MPa}$. In particular, a larger response of the maximum and minimum principle stresses of the lining within a range of $10 \mathrm{~m}$ nearing the bedrock-overburden interface are observed (Figure 15), with the maximum and minimum principle stresses of the lining reaching 6.3 $\mathrm{MPa}$ and $-11.45 \mathrm{MPa}$, respectively. 


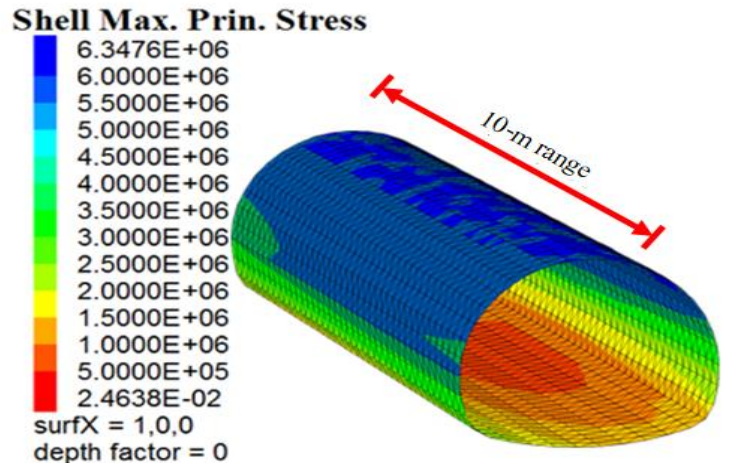

(a) Contour of maximum principle stress

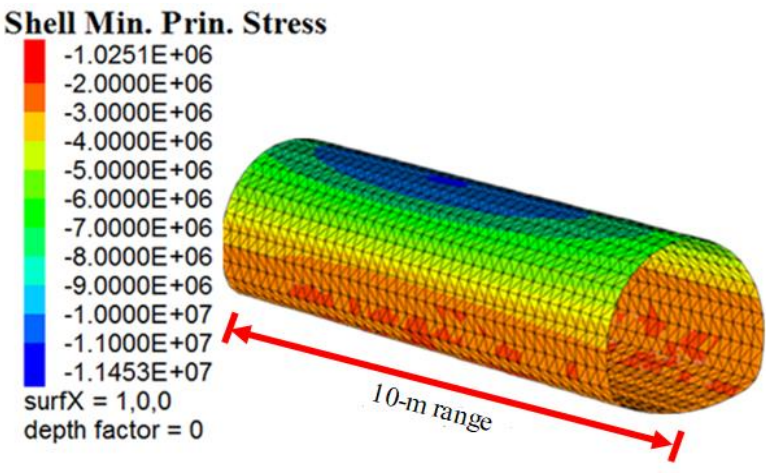

(b) Contour of minimum principle stress

Figure 15. Contour of principal stresses within $10 \mathrm{~m}$ nearing the bedrock-overburden interface

According to code for design of concrete structures (GB 50010-2010) [24], the compressive strength of C25 concrete is $16.7 \mathrm{MPa}$, and tensile strength is $1.78 \mathrm{MPa}$. Obviously, maximum compressive stress meets the requirements of the strength standard. But many parts of lining of maximum tensile stress exceeds the tensile strength of concrete, thus resulting in the concrete is extremely prone to crack. Especially, in the vicinity of the bedrock-overburden interface, the tensile stress of the vault is the greatest one, followed by the vault, arch shoulder, sidewall, and arch foot. Meanwhile, the cracks extend from the vault to arch foot (Figure 14).

\subsubsection{Peak shear force nearing the} bedrock-overburden interface. Figure 16 shows the curves of shear peaks at different parts of the lining along the tunnel axis. As shown in Figure 16, some conclusions can be presented as following:

(1) The peak shear force in the near-mountain side is generally larger than that in another side, thus indicating that the asymmetric pressure has a greater influence on the distribution of shear force. the peak shear force at about $10 \mathrm{~m}$ from the portal is relatively larger due to the asymmetric pressure and amplification effect of seismic waves nearing tunnel portals [25].

(2) In the range of $40-45 \mathrm{~m}$ from the portal (bedrock-overburden interface), the peak shear force at different parts of the lining increase significantly. This indicates that the overburden above the interface sided under the seismic loading, thus exerting a huge additional shear force on the lining nearby and leading to the lining cracking.

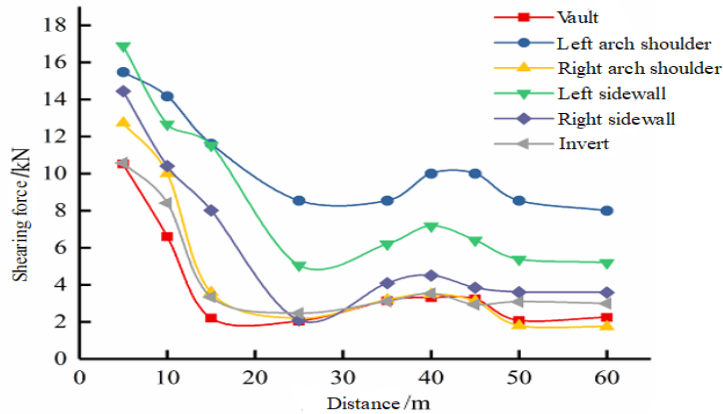

Figure 16. Curve of peak shear force vs. distance at different parts of lining

4.4.3. Seismic damage mechanism. As shown in Figs 15 and 16, the primary reasons for the circumferential rupture zone are two-fold: (1) tensile and compressive stress concentration at the vault nearing the bedrock-overburden interface results in the first cracking of vault; (2) the huge shear force occurred in the bedrock-overburden interface due to the landslide.

Due to the difference in the geotechnical properties on both sides of the bedrock-overburden interface, there is an obvious inconsistent in strain. Under horizontal seismic inertia force, the slope began to slide [26]. When the slope slides along the bedrock-overburden interface, a huge shear force is applied to the lining, as shown in Figure 17. This can lead to: (1) when the tensile and compressive stresses of the vault exceed the strength of the concrete, the vault cracks first; (2) under the axial seismic loading, the lining at arch shoulder is subjected to alternate tension and compression, thereby making the internal shear strain and tensile strain gradually accumulate. When the accumulated shear and tensile strain and exceed the ultimate strain of concrete, the arch shoulder begin to crack; (3) the cracks further extended to the sidewall and arch foot, which has an agreement with the results of Huang et al. [27]; When the fissures were connected, the circumferential rupture zone formed. 


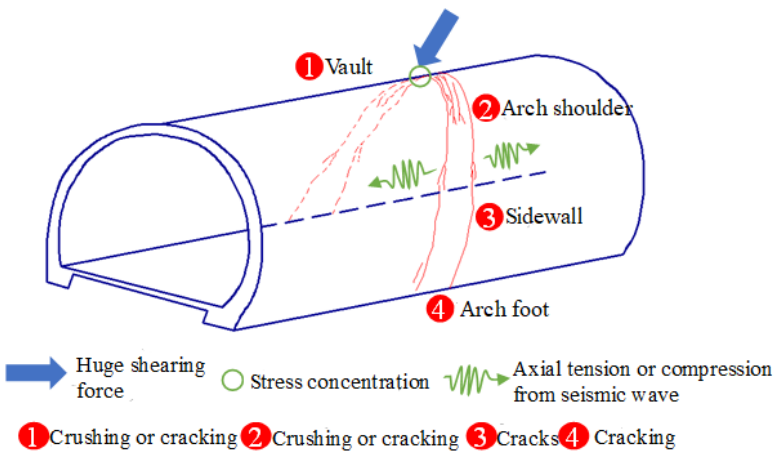

Figure 17. Schematic graph of the development of circumferential cracks in lining

\section{Conclusions}

Based on the seismic damage characteristic in the Longxi tunnel, the seismic damage mechanism of the slope and lining at the tunnel portal section is analyzed with numerical simulation. The main conclusions are as follows:

The slope cracking at the tunnel portal is caused by the extremely low strength of soil at the top-back slope, under the horizontal seismic inertia force. The reason for the landslide at the tunnel portal is that the oblique component of the horizontal seismic inertia force exceeds the shear strength of the slope after the slope cracks, thus leading to the crack gradual extending and expanding of the cracks.

The rockfalls and collapses at the tunnel portal are caused by the continuous and alternate seismic inertia force, and the tensile stress in the loose soil and strongly weathered rock on the slope surface is gradually accumulated. Once exceeding the tensile strength of rock and soil itself, they are thrown to the slope foot.

Transverse and oblique cracks of lining are caused by the alternate tension and compression or bending deformation along the tunnel axis, resulting in the strain accumulation in the lining. When the accumulated tensile strain exceeds the ultimate strain of concrete, the lining will crack laterally.

The longitudinal cracks of lining at the tunnel portal section are caused by additional alternate bending moments under the transverse seismic loading. When these transverse deformation modes act jointly, different parts of the lining (vault, arch shoulder, sidewall, arch foot and pavement) are subjected to alternate tension and compression in a very short time, which significantly reduces the strength of the concrete and makes it crack longitudinally.

The circumferential rupture zone is caused by the huge shear force produced by the landslide, which results in the concentrated tensile and compressive stress in the vault at the bedrock-overburden interface. When the stress exceeds the tensile strength of the concrete, the vault will crack first. Under the alternate tension and compression of axial seismic loading, the cracks extend from the vault to arch foot, thus forming the circumferential rupture zone.

\section{References}

1. Du X.L., Xu Z.G., Xu C.S., et al. (2018) Inertia force-displacement method for seismic analysis of shallow buried underground structures. Chinese Journal of Geotechnical Engineering, 40(4): 584591.

2. Dong L., Wang L.M., Xia K., et al. (2017) Comparison of CPT-based and SPT-based liquefaction discrimination methods by Taiwan Chi-Chi earthquake data. Rock and Soil Mechanics, 38(12): 3643-3648.

3. Sun Y.W., Li P., Bo J.S., et al. (2010) Damage investigation and cause analysis of Longxi tunnel in Wenchuan great earthquake. World Earthquake Engineering, 26(Supp): 187-191.

4. Tao L.J., Li S.L., Hou S., et al. (2016) Shaking table test for seismic response in portal section of mountain tunnel. World Earthquake Engineering, 32(4): 7-16.

5. Zhao X., Hua C.Y., Zhao M., et al. (2017) Study on seismic stability of a tunnel portal section based on the strength reduction method. China Earthquake Engineering Journal, 39(6): 1029-1036.

6. Sui C.Y., Gao B., Shen Y.S., et al. (2017) Shaking table tests and analysis on tunnel structures with high steep slope. Journal of Vibration and Shock, 36(19): 186-194.

7. Liu G.Q., Chen J.T., Xiao M., et al. (2018) Dynamic response simulation of lining structure for tunnel portal section under seismic load. Shock and Vibration, (6): 1-10.

8. Wu D., Gao B., Shen Y.S., et al. (2015) Damage evolution of tunnel portal during the longitudinal propagation of Rayleigh waves. Natural Hazards, 75(3): 2519-2543.

9. Shen Y.S., Gao B., Yang X.M., et al. (2014) Seismic damage mechanism and dynamic deformation characteristic analysis of mountain tunnel after Wenchuan earthquake. Engineering Geology, 180: 85-98.

10. Cui G.Y., Wang M.N., Yu L., et al. (2013) Seismic damage and mechanism of portal structure of highway tunnels in Wenchuan Earthquake, Chinese Journal of Geotechnical Engineering, 35(6): 10841091.

11. Chen G.H., Li H.Q., Zhong Y., et al. (2008) Seismic tunnel damage investigation and analysis of G213 Dujiangyan to wenchuan section. Xi Nan Gong Lu, 4: 114-119.

12. LI T.B. (2012) Damage to mountain tunnels related to the Wenchuan earthquake and some suggestions for aseismic tunnel construction. Bulletin of Engineering Geology \& the Environment, 71: 297308.

13. Wang W.L., Wang T.T., Su J.J., et al. (2001) Assessment of damage in mountain tunnels due to the Taiwan Chi-Chi Earthquake. Tunnelling and Underground Space Technology, 16: 133-150. 
14. Cui G.Y., Wu X.G., Wang M.N. et al. (2017) Earthquake Damages and Characteristics of Highway Tunnels in the 8.0-Magnitude Wenchuan Earthquake. Modern Tunnelling Technology, 54(2): 9-16.

15. Zang W.J. (2017) Damage to Highway Tunnels Caused by the Wenchuan Earthquake. Modern Tunnelling Technology, 54(2): 12-25.

16. Fan Z.F., Zhang J.C., Xu H. (2019) Theoretical study of the dynamic response of a circular lined tunnel with an imperfect interface subjected to incident SV-waves. Computers and Geotechnics 110: 308-318.

17. Fan Z.F., Zhang J.C., Xu H., et al. (2019) Transmission of normal p-wave across a single joint based on $g-\lambda$ model. Shock and Vibration. 2019:110 .

18. Xu J.S., Xu H., Sun R.F., et al. (2020) Seismic risk evaluation for a planning mountain tunnel using improved analytical hierarchy process based on extension theory. Journal of Mountain Science 17(1): 244-260.

19. Ye H.L., Zheng Y.R., Du X.L., et al. (2012) Shaking table model test and numerical analysis on dynamic failure characteristics of slope. China Civil Engineering Journal, 45(9): 128-135.

20. Fan G., Zhang J.J., Fu X., et al. (2015) Large-scale shaking table test on dynamic response of bedding rock slopes with silt intercalation. Chinese Journal of Rock Mechanics and Engineering, 34(9): 17501757.

21. Hashash Y.M.A., Hook J.J., Schmidt B., et al. (2001) Seismic design and analysis of underground structures. Tunnelling and Underground Space Technology, 16(4): 247-293.

22. Xu H., Li T.B., Xia L., et al. (2016) Shaking table tests on seismic measures of a model mountain tunnel. Tunnelling and Underground Space Technology, 60: 197-209.

23. Xu Y.L., Gu X.L., et al. Judgment and treatment of cracks in concrete structure engineering[M]. Beijing: China Architecture \& Building Press, 2010.

24. Ministry of housing and urban-rural development of the People's Republic of China. Code for design of concrete structures: GB 50010-2010[S]. Beijing: China Architecture \& Building Press, 2010.

25. Xu H., Li T.B., Wang D., et al. (2013) Study of seismic responses of mountain tunnels with 3D shaking table model test. Chinese Journal of Rock Mechanics and Engineering, 32(9).

26. Li Z.Z., Shen J.H., Gu T., et al. (2009) Essentials of the excavation and monitoring for twin closely-spaced tunnels embedded in slidding rock. Modern Tunnelling Technology, 46(5): 40-44.

27. Huang H.W., Liu D.J., Xue Y.D., et al. (2013) Numerical analysis of cracking of tunnel linings based on extended finite element. Chinese Journal of Geotechnical Engineering, 35(2): 266-275. 